\title{
Antibiogram and characterization of resistance markers among Escherichia coli Isolates from urinary tract infections
}

\author{
Yashwant Kumar, Shivani Sood, Anshu Sharma and Kavaratty Raju Mani \\ National Salmonella and Escherichia Centre, Central Research Institute, Kasauli, Himachal Pradesh, India
}

\begin{abstract}
Introduction: Urinary tract infection is the most frequently diagnosed kidney and urologic disease, and Escherichia coli is by far its most common etiological agent. Uropathogenic E. coli are responsible for approximately $90 \%$ of urinary tract infections seen in individuals with ordinary anatomy therefore, it is essential to review the antibiogram of uropathogenic $E$. coli periodically to help clinicians decide on the appropriate therapy.

Methodology: We evaluated E. coli isolated from urinary tract infections at the National Salmonella and Escherichia Centre for antibiogram, plasmid transferability and stability of resistance markers.

Results: In total, $90.9 \%$ of the isolates were found to be sensitive to nitrofurantoin while the highest proportion of the isolates was found to be resistant to nalidixic acid. Minimum inhibitory concentrations of all antimicrobials for different isolates were well within the limits specified by the Clinical and Laboratory Standards Institute. Resistance against tetracycline was not transferred either by conjugation and transformation. Streptomycin resistance was found to be lost in the maximum number of tested isolates showing loss at the $10^{\text {th }}, 15^{\text {th }}$ and $20^{\text {th }}$ passages.

Conclusion: Changing trends in antibiotic resistance necessitates the periodic generation of antibiogram data to help health authorities revise treatment strategies for urinary tract infections caused by E. coli.
\end{abstract}

Key words: Escherichia coli; urinary tract infections; antibiogram

J Infect Dev Ctries 2013; 7(7):513-519. doi:10.3855/jidc.2706

(Received 21 April 2012 - Accepted 29 July 2012)

Copyright $(\mathcal{C} 2013$ Kumar et al. This is an open-access article distributed under the Creative Commons Attribution License, which permits unrestricted use, distribution, and reproduction in any medium, provided the original work is properly cited.

\section{Introduction}

"Urinary tract infection" (UTI) is a broad term that encompasses either asymptomatic microbial colonization of urine or symptomatic infection with microbial invasion and inflammation of the urinary tract [1]. However, from a microbiological perspective, urinary tract infection exists when pathogenic microorganisms are detected in the urine, urinary bladder, urethra, kidney, or prostate [2].

UTI is one of the most common human infections $[3,4]$ and a major cause of morbidity and mortality [5]. Bacteria responsible for UTI often originate from the fecal and perineal microbiota [4]. Serotypes of Escherichia coli consistently associated with UTI are designated as uropathogenic E. coli (UPEC) [5].

Antimicrobials are critical in the treatment of bacterial infections. A drastic decrease in the mortality and morbidity resulting from the use of antimicrobials during 1980s led to complacence among the medical fraternity [6]. The result was misuse and inappropriate use of antimicrobials, with emphasis on curative medicines at the cost of disease preventable measures, leading to the emergence of bacterial resistance [7].
The emergence and spread of antimicrobial resistance is a cause of increasing concern [8]. It is one of the major causes of failure in treatment of infectious diseases that results in increased morbidity, mortality, and economic burden [9]. Urinary infections are the second most common among human infections and the development of bacterial resistance further complicates the therapy. Organisms tend to develop unpredictable resistance patterns thereby indicating the necessity for constant surveillance of antibiograms to observe trends among UPEC isolates.

\section{Methodology}

Bacterial Strains

Fifty-five E. coli strains isolated from urine cultures from people with UTI constituted the material for the study. Samples were received from different parts of the country over a period of two years (January 2007 to December 2008) at the National Salmonella and Escherichia Centre (National Reference Laboratory), Central Research Institute, Kasauli, India. The centre received 28 and 27 UPEC isolates in the years 2007 and 2008, respectively. All 
isolates were identified by conventional biochemical tests [10] and confirmed by serotyping [11]. The difference between the proportion of resistance to various antibiotics in the year 2008 and 2009 was statistically evaluated using the $\mathrm{z}$-test for proportions.

\section{Antimicrobial susceptibility testing}

The susceptibility patterns of the isolates were determined by disc diffusion method using the following antimicrobials (Hi Media Laboratories, Pvt. Ltd., Mumbai, India): ampicillin $(10 \mu \mathrm{g})$, ceftazidime $(30 \mu \mathrm{g})$, ciprofloxacin $(5 \mu \mathrm{g})$, gentamicin $(10 \mu \mathrm{g})$, nalidixic acid $(30 \mu \mathrm{g})$, tetracycline $(30 \mu \mathrm{g})$, nitrofurantoin $(300 \mu \mathrm{g})$, norfloxacin $(10 \mu \mathrm{g})$, amoxycillin/clavulanic acid $(20 / 10 \mu \mathrm{g})$, piperacillin/tazobactum $(100 / 10 \mu \mathrm{g})$, streptomycin $(10$ $\mu \mathrm{g}), \quad$ and trimethoprim/sulfamethoxazole $(1.25 / 23.75 \mu \mathrm{g})$, according to the CLSI guidelines and interpretative criteria [12]. Minimum inhibitory concentrations (MIC) were determined by agar dilution test [13] using antimicrobials (Hi Media Laboratories, Pvt. Ltd., Mumbai, India) or by E-test (Hi Media Laboratories, Pvt. Ltd., Mumbai, India).

\section{Transferability of $R$ plasmids}

Transfer of resistance was assayed using a standard rifampin-resistant $E$. coli recipient, CGSC $6576\left(\mathrm{~F}^{-}, \lambda^{-}, \operatorname{rec} A 1, I N(r r n D-r r n E) 1, \operatorname{rpoB} 331\right.$ (rifR), hsdR19), kindly supplied by Dr. John Wertz from Coli Genetic Stock Centre, Yale, USA), according to the method described by Robertson and colleagues [14]. Plasmid DNA was isolated as described by Engebrecht et al. [15] and transformation was performed using a HMS174 ( $\mathrm{F}^{-}$recAl hsdR $\left(\mathrm{r}_{\mathrm{K} 12}{ }^{-} \mathrm{m}_{\mathrm{K} 12}{ }^{+}\right)\left(\mathrm{Rif}^{\mathrm{R}}\right)$ competent cell kit (Novagen, Darmstadt, Germany) per the manufacturer's instructions.

\section{Size determination and stability of $R$ plasmids}

Isolation of plasmid DNA was performed as described by Engebrecht et al. [15] and plasmid DNA was electrophoresed in $0.8 \%$ agarose gel. HindIII lambda DNA digest was used as the molecular weight standard. Stability of the resistance markers in isolates and transconjugants was determined as described by Wantabe and Ogata [16]. All strains were subcultured regularly on a daily basis for 25 days and the stability of resistance patterns was determined intermittently by disc diffusion method.

\section{Results}

Six distinct serogroups were found among the $E$. coli strains studied. Most of the isolates belonged to the serogroup $\mathrm{O} 4$ followed by $\mathrm{O} 1, \mathrm{O} 2, \mathrm{O} 25$ and $\mathrm{O} 6$ with the least proportion belonging to O75 (Table 1). Higher numbers of isolates were found to be isolated from females $(37 / 67.3 \%)$ as compared to those from males (18/32.7\%) (Table 2). Moreover, the maximum proportion of isolates was from the age group of 11 to 50 years in males $(12 / 66.6 \%)$ as well as in females (21/56.8) (Table 2). A high level of resistance was found against nalidixic acid (48/87.3\%), followed by ampicillin (47/85.5\%), norfloxacin (41/74.5\%), amoxycillin/clavulanic acid $(41 / 74.5 \%)$, tetracycline $(37 / 67.3 \%)$ and trimethoprim/sulfamethoxazole $(37 / 67.3 \%)$, while all isolates were found to be sensitive to nitrofurantoin and piperacillin/tazobactum in both the years collectively (Figure 1). None of the isolates was sensitive to all antimicrobials tested (Table 3). An increase in the proportion of isolates resistant to nalidixic acid ( $\mathrm{p}=0.246)$, streptomycin ( $\mathrm{p}$ $=0.109)$, and tetracycline $(\mathrm{p}=0.103)$ was observed in the year 2008 as compared to that in 2007, but it was not found to be statistically significant when compared using the z-test for proportions (Table 3). The MIC values for all antimicrobials for resistant isolates were found to be the same in both years except for streptomycin $(60 \mu \mathrm{g} / \mathrm{ml}$ to $240 \mu \mathrm{g} / \mathrm{ml})$, tetracycline (30 $\mu \mathrm{g} / \mathrm{ml} \quad$ to $240 \quad \mu \mathrm{g} / \mathrm{ml}$ ) and trimethoprim/sulfamethoxazole $(75 / 240 \mu \mathrm{g} / \mathrm{ml})$, which showed higher values in 2008 as compared to those in 2007 (Table 4).

The percentage transfer of resistance markers ranged from $0 \%$ to $75.9 \%$ and $0 \%$ to $93.5 \%$ through conjugation and transformation, respectively (Figure 2). Resistance markers for tetracycline, ciprofloxacin, norfloxacin, trimethoprim/sulfamethoxazole, amoxycillin/clavulanic acid and nalidixic acid were not found to be transferred in both cases. Out of a total number of 55 isolates, loss of resistance markers was observed only in $13(23.6 \%)$ of them. All isolates were found to harbour 1 to 7 plasmids with sizes ranging approximately between 3 and $23 \mathrm{~Kb}$. The most common plasmid of approximately $23 \mathrm{~Kb}$ was found to be present in all isolates. Streptomycin resistance was found to be lost in maximum proportion of the isolates $(6 / 46.2 \%)$ followed by trimethoprim/sulfamethoxazole $(3 / 23.1 \%)$, gentamicin $(2 / 15.4 \%)$ and tetracycline $(2 / 15.4 \%)$, whereas ampicillin, ceftazidime and tetracycline resistance was found to be lost in the lowest proportion of isolates $(1 / 7.7 \%)$. 
Figure 1. Antibiogram of UPEC received at NSEC during 2007-2008

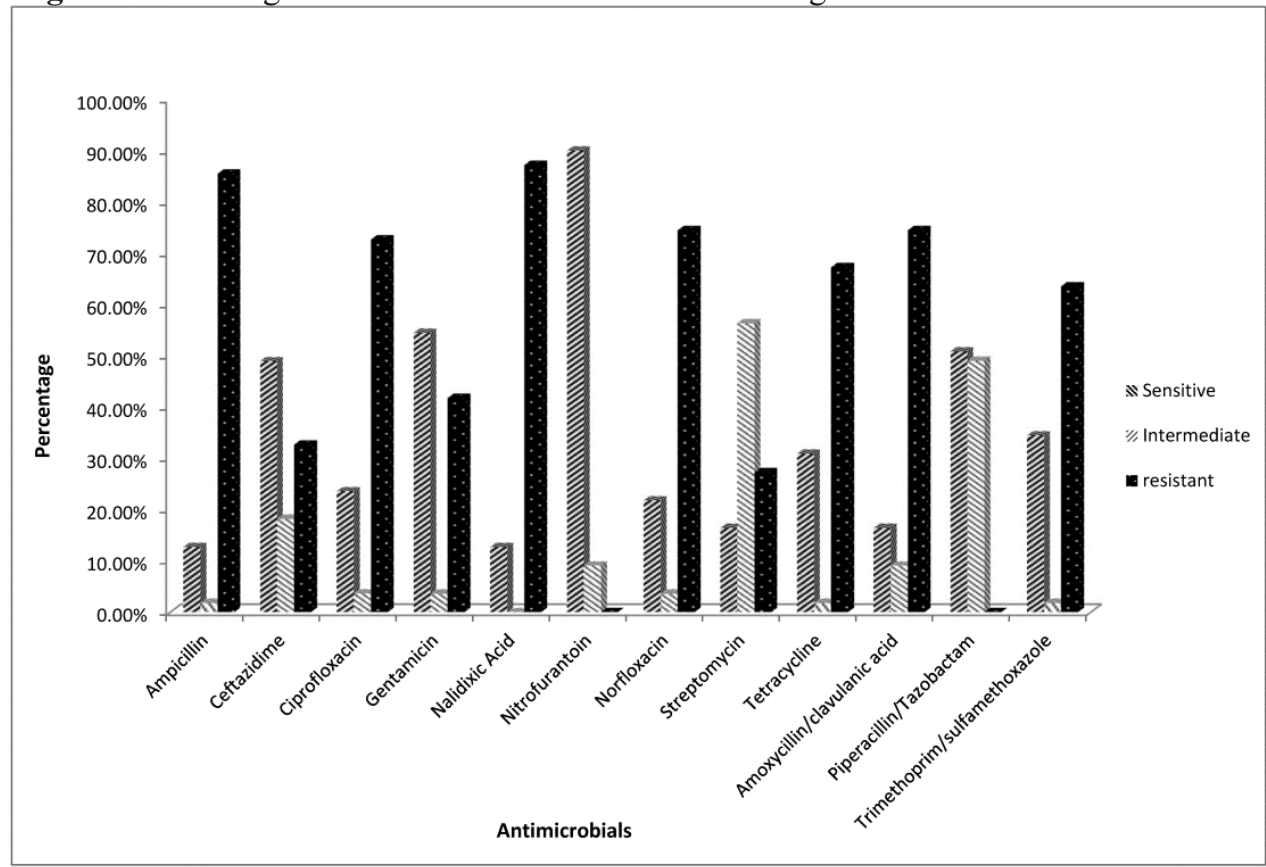

Proportion of susceptible intermediate and resistant isolates of UPEC received at National Salmonella and Escherichia center during January 2007 to December 2008. Highest resistance was found against nalidixic acid followed by ampicillin, amoxyclav and noflaxacin. No resistant isolate was found for nitrofurnation and p-tazobactum.

Figure 2. Transfer of resistance markers through conjugation and transformation

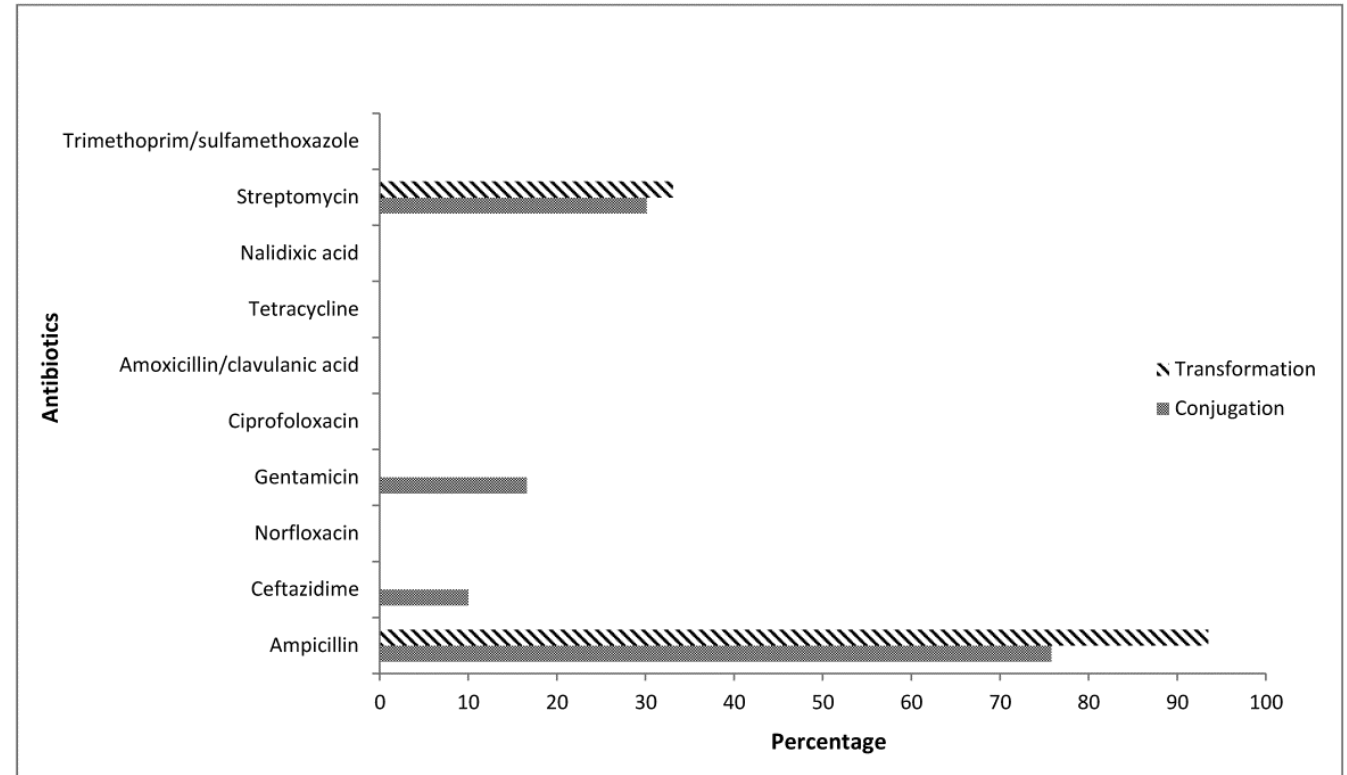

Transfer of resistance to different antimicrobials through conjugation and transformation. Resistance markers for ampicillin and streptomycin was found to be transferred by conjugation and transformation whereas that for gentamicin and cefazidime was found to be transferred by conjugation only. Resistance to cotrimozazole, nalidixic acid, tetracycline, amoxyclav and norfloxacin was not transferred by both methods. 
Table 1. Serogroups found among UPEC strains analyzed

\begin{tabular}{|c|c|c|}
\hline Serogroup & Number of isolates & Percentage (\%) \\
\hline O1 & 14 & 25.5 \\
\hline O2 & 9 & 16.4 \\
\hline O4 & 22 & 40 \\
\hline O6 & 3 & 5.6 \\
\hline O25 & 5 & 9.1 \\
\hline O75 & 2 & 3.6 \\
\hline
\end{tabular}

Table 2. Age and sex distribution of UPEC

\begin{tabular}{|c|c|c|c|c|}
\hline \multirow{2}{*}{ Sex } & \multirow{2}{*}{$\begin{array}{c}\text { Number of patients } \\
\mathbf{n}(\%)\end{array}$} & $\mathbf{3}$ Age (years) \\
\cline { 3 - 5 } & $18(32.7 \%)$ & $0(0 \%)$ & $12(66.6 \%)$ & $6(33.3 \%)$ \\
\hline Male & $37(67.3 \%)$ & $9(24.3 \%)$ & $21(56.8 \%)$ & $7(18.9 \%)$ \\
\hline Female & &
\end{tabular}

Table 3. UPEC response to antimicrobials

\begin{tabular}{|l|c|c|c|c|c|c|}
\hline \multirow{2}{*}{ Antibiotics } & \multicolumn{2}{|c|}{$\begin{array}{c}\text { Sensitive Isolates } \\
\text { N (\%) }\end{array}$} & \multicolumn{2}{c|}{$\begin{array}{c}\text { Intermediate Isolates } \\
\text { N (\%) }\end{array}$} & \multicolumn{2}{c|}{$\begin{array}{c}\text { Resistant Isolates } \\
\text { N (\%) }\end{array}$} \\
\cline { 2 - 7 } & $\mathbf{2 0 0 7}$ & $\mathbf{2 0 0 8}$ & $\mathbf{2 0 0 7}$ & $\mathbf{2 0 0 8}$ & $\mathbf{2 0 0 7}$ & $\mathbf{2 0 0 8}$ \\
\hline Ampicillin & $4(14.3 \%)$ & $3(11.1 \%)$ & $0(0 \%)$ & $1(3.7 \%)$ & $24(85.7 \%)$ & $23(85.2 \%)$ \\
\hline Ceftazidime & $15(53.6 \%)$ & $12(44.4 \%)$ & $7(25.0 \%)$ & $3(11.1 \%)$ & $6(21.4 \%)$ & $12(44.4 \%)$ \\
\hline Ciprofloxacin & $6(21.4 \%)$ & $7(25.9 \%)$ & $1(3.6 \%)$ & $1(3.7 \%)$ & $21(75.0 \%)$ & $20(74.4 \%)$ \\
\hline Gentamicin & $17(60.7 \%)$ & $13(48.1 \%)$ & $0(0 \%)$ & $2(7.4 \%)$ & $11(39.3 \%)$ & $12(44.4 \%)$ \\
\hline Nalidixic Acid & $5(17.8 \%)$ & $2(7.4 \%)$ & $0(0 \%)$ & $0(0 \%)$ & $23(82.2 \%)$ & $25(92.6 \%)$ \\
\hline Nitrofurantoin & $27(96.4 \%)$ & $23(85.2 \%)$ & $1(3.6 \%)$ & $4(14.8 \%)$ & $0(0 \%)$ & $0(0 \%)$ \\
\hline Norfloxacin & $5(17.8 \%)$ & $7(25.9 \%)$ & $0(0 \%)$ & $2(7.4 \%)$ & $23(82.2 \%)$ & $18(66.7 \%)$ \\
\hline Streptomycin & $6(21.4 \%)$ & $3(11.1 \%)$ & $17(60.7 \%)$ & $14(51.8 \%)$ & $5(17.8 \%)$ & $10(37.0 \%)$ \\
\hline Tetracycline & $12(42.8 \%)$ & $5(18.5 \%)$ & $0(0 \%)$ & $1(3.7 \%)$ & $16(57.2 \%)$ & $21(77.8 \%)$ \\
\hline Amoxicillin/clavulanic acid & $4(14.3 \%)$ & $5(18.5 \%)$ & $3(10.7 \%)$ & $2(7.4 \%)$ & $21(75.0 \%)$ & $20(74.1 \%)$ \\
\hline Piperacillin/tazobactam & $15(53.6 \%)$ & $13(48.1 \%)$ & $13(46.4 \%)$ & $14(51.9 \%)$ & $0(0 \%)$ & $0(0 \%)$ \\
\hline $\begin{array}{l}\text { Trimethoprim/ } \\
\text { sulfamethoxazole }\end{array}$ & $9(32.1 \%)$ & $10(37.0 \%)$ & $0(0 \%)$ & $1(3.7 \%)$ & $19(67.8 \%)$ & $16(59.2 \%)$ \\
\hline
\end{tabular}


Table 4. Range of minimum inhibitory concentration of antimicrobials for UPEC strains

\begin{tabular}{|c|c|c|c|c|c|c|}
\hline \multirow{2}{*}{ Antibiotics } & \multicolumn{2}{|c|}{ Sensitive } & \multicolumn{2}{|c|}{ Intermediate } & \multicolumn{2}{|c|}{ Resistant } \\
\hline & 2007 & 2008 & 2007 & 2008 & 2007 & 2008 \\
\hline Ampicillin & $3.75-7.5$ & $0.93-7.5$ & No Isolate & $15-30$ & 60 & 60 \\
\hline Ciprofloxacin & $0.004-3.75$ & $0.06-1.87$ & $15-30$ & 15 & 60 & 60 \\
\hline Ceftazidime & $0.03-0.58$ & $0.03-0.23$ & 1.87 & 1.87 & 7.5 & 7.5 \\
\hline Gentamycin & $1.87-3.75$ & $0.93-1.87$ & No Isolate & $7.5-15$ & 30 & 30 \\
\hline Nalidixic acid & $0.93-3.75$ & $1.87-3.75$ & No Isolate & No Isolate & 240 & $60-240$ \\
\hline Nitrofurantoin & $3 . .75-15.0$ & $0.93-7.5$ & 60 & $30-60$ & No Isolate & No Isolate \\
\hline Norfloxacin & $0.001-1.87$ & $0.05-1.87$ & No Isolate & $7.5-8.75$ & $120-240$ & $60-240$ \\
\hline Streptomycin & 10.0 & $2.5-10$ & $3.75-30$ & $1.87-30$ & 60 & $60-240$ \\
\hline Tetracycline & $0.93-3.75$ & $0.93-3.75$ & No Isolate & 7.5 & $30-60$ & $30-240$ \\
\hline Amoxicillin/clavulanic acid & $\begin{array}{c}3.75 / 1.87-1.87 / \\
0.93\end{array}$ & $3.75 / 1.875$ & $15 / 7.5$ & $30 / 7.5$ & $60 / 30$ & $60 / 30$ \\
\hline Piperacillin/tazobactam & $3.75 / 0.46-1.87 / 0.46$ & $7.5 / 0.93$ & $30 / 4$ & $30 / 4$ & No Isolate & No Isolate \\
\hline $\begin{array}{l}\text { Trimethoprim/ } \\
\text { sulfamethoxazole }\end{array}$ & $0.93 / 15-1.875 / 30$ & $0.93 / 30$ & No Isolate & $3.75 / 60$ & $7.5 / 120$ & $7.5 / 240$ \\
\hline
\end{tabular}

\section{Discussion}

Urinary tract infection is emerging as an important community acquired and nosocomial bacterial infection. Moreover, antimicrobial resistance to various classes of antimicrobials continues to be a major health problem in different parts of the world [17-20], including India [21-24], posing a therapeutic challenge for health authorities. Antimicrobial resistance among UPEC shows considerable variations during different time periods and in different areas. The problem becomes further complicated with the emergence of ESBL producing UPEC [25,26].

More isolates were recovered from females $(37 / 67.3 \%)$ as compared to males $(18 / 32.7 \%)$. This result may be attributed to a high risk of infection in females due to a short urethra and its proximity to the anal opening. Drug resistance, particularly to commonly available drugs such as ampicillin, trimethoprim/sulfamethoxazole, gentamicin, ceftazidime and norfloxacin, is of great concern and further reduces effective therapeutic options in the treatment of UTI. However, isolates did not show any resistance to nitrofurantoin and piperacillin/tazobactum, which is in contrast to the results obtained in some other patient groups [4]. None of the isolates was sensitive to all antimicrobials tested, since for each of them there are strains with intermediate and/or resistant responses (Table 3), and therefore show a high level of antimicrobial resistance in UPEC. However, nitrofurantoin remains the drug of choice with high sensitivity (50/90.9\%) (Figure 1).

Ceftazidime $(p=0.069)$, gentamicin $(p=0.696)$, nalidixic acid $(p=0.246)$, streptomycin $(p=0.109)$, and tetracycline $(\mathrm{p}=0.103)$ exhibited an increase in resistance in 2008 compared to the resistance seen for these antibiotics in the previous year, but the difference was not found to be statistically significant when compared using z-test for proportions. The rest of the antimicrobials, however, showed almost equal resistance percentages to those noted previously and resistance to these antimicrobials was also higher than that observed by others [4], exhibiting an increase in drug resistance. This increase in resistance is widely attributed to excessive and inappropriate use of antimicrobials.

Values of minimum inhibitory concentrations for sensitive, intermediate and resistant isolates for different antimicrobials used in the study lay well within the specified ranges given recommended by the Clinical and Laboratory Standards Institute [27], 
except streptomycin (Table 4), for which there is no clear consensus on the interpretation of susceptibility test results.

Conjugative transfer of antimicrobial resistance was found to be quite prominent. Tetracycline was not found to be transferrable by conjugation and transformation, and this observation is in concordance with those obtained in other studies [28,29]. This result may be due to the presence of a tetracycline resistance marker on a large-sized or defective plasmid [30,31]. Moreover, ciprofloxacin and nalidixic acid resistance were not transferred through conjugation and transformation, and this may be due to the chromosomal origin of nalidixic acid and ciprofloxacin resistance [32]. Tetracycline, norfloxacin, amoxycillin/clavulanic acid, trimethoprim/sulfamethoxazole, and ciprofloxacin thus have a greater advantage against resistance, as resistance to these are not transferrable by horizontal gene transfer thereby restricting the spread of drug resistance.

Owing to the scarcity of literature on the stability of resistance markers, the same was determined in uropathogenic E. coli isolates. Partial loss of the Rplasmid was observed in 13 isolates. Streptomycin resistance was found to be most susceptible to loss during subculture, followed by trimethoprim/sulfamethoxazole, gentamicin, and ampicillin. Other resistance markers were found to be quite stable thereby increasing the chances of conjugational transfer and may therefore facilitate the spread and maintenance of antimicrobial resistance.

\section{Conclusion}

Many variations exist among uropathogenic E. coli in terms of antibiogram profile. Periodic formulation and review of antimicrobial policies are therefore required for controlling the development and dissemination of drug resistance. Continuous evolution of antimicrobial resistance is worrisome and mandates both further surveillance and new approaches to slow down the emergence and upsurge of antimicrobial resistance. Rationales for prudent antimicrobial use, followed by discrete adherence to the same, are needed. Moreover, due to the high prevalence of variability among antibiograms, empirical selection should be based on the knowledge of local prevalence and individual sensitivity rather than on universal guidelines.

\section{Acknowledgements}

The authors thank the heads of all the laboratories that referred E. coli strains to the National Salmonella and Escherichia Centre (National Reference Laboratory), Central Research Institute, Kasauli, India. The technical assistance of $\mathrm{Mr}$ Krishan Dutt and $\mathrm{Mr}$ Khushnihal Kaushal is also acknowledged. Thanks are due to Mr Jiwa Ram for supplying media and biochemicals for biotyping.

\section{References}

1. Calvin MC (2000) Urinary Tract Infections and Pyelonephritis. In: Goldman L, Ausiello D, Editors. Cecil Textbook of medicine. Philadelphia: Saunders Elsevier, p.138.

2. Stamm EW (2001) Urinary Tract Infection and Pyelonephritis. In: Fauci AS, Braunwald E, Kasper DL, Hauser AL, Longo DL, Jameson L, Loscalzo J, Editors. Harrison's Principle of Internal medicine. New York: McGraw-Hill Companies Inc. 1620-1626.

3. Rajni E, Rawat U, Malhotra VL Mehta G (2008) Occurence and detection of Amp C $\beta$-lactamases among clinical isolates of Escherichia coli and $K$. pneumoniae causing UTI. J Commn Dis 40: 21-25.

4. Naveen R, Mathai E (2005) Some virulence characteristics of uroapthogenic Escherichia coli in different patient groups. Ind J Med Res 122: 143-147.

5. Raksha R, Srinivasa H, Macaden RS (2003) Occurrence and characterization of uropathogenic Escherichia coli in urinary tract infections. Ind J Med Microbiol 21: 102-10.

6. Kapil A (2005) The challenge of antibiotic resistance; Need to contemplate. Ind J Med Res 121: 102-107.

7. Cohen ML (2000) Changing patterns of infectious diseases. Nature 406: 762-767.

8. Gupta K (2002) Addressing antibiotic resistance. Am J Med 113: 295-345.

9. Bauza E, Cercenado E (2002) Klebsiella and Enterobacter Antibiotic resistance and treatment implications. Semin Respis Infecti 17: 215-230.

10. William RH (1994) Group 5: Facultative anaerobic Gram negative rods. In: Bergey's Manual of Determinative Bacteriology. 9th 270 ed. Baltimore: Williams and Wilkins, p. 175-201.

11. Orskov K and Orskov I (1984) Serotyping of Escherichia coli. In: T. Bergon (Editor), Methods in Microbiology, Vol. 14. Academic Press, London, p. 43-122.

12. National Committee for Clinical Laboratory Standards (2000) Performance Standards for antimicrobial disc susceptibility tests. Approved standards, $7^{\text {th }}$ ed. NCCLS document M2-A6. NCCLS: Wayne, PA.

13. Clinical and Laboratory Standards Institution (2006) Methods for Dilution Antimicrobial Susceptibility Tests for Bacteria that Grow Aerobically. Approved standards, CLSI document M7-A7. CLSI: Wayne PA.

14. Robertson FM, Addy ME, Mensah P, Crupper SS (2002) Molecular characterization of antibiotic resistance in clinical Salmonella typhi isolated in Ghana. FEMS Micobiol Lett 215: 249-253.

15. Engebrecht J, Brent R, Kaderbhai MA (2003) Minipreps of plasmid DNA. In: Current protocols in molecular biology. Ausubel FM, Brent R, Kingston RE, Moore DD, Seidman JG, Smith JA, Struhl K (eds.), John Wiley \& Sons Inc. Section II, Unit 1.6 
16. Watanabe T, Ogata Y (1970) Genetic Stability of Various Resistance Factors in Escherichia coli and Salmonella typhimurium. J Bacteriol 102: 363-368.

17. Foxman B (2010) The epidemiology of urinary tract infection. Nat Rev Urol 7: 653-660.

18. Oliveira FA, Paludo KS, Arend LNVS, Farah SMSS, Pedrosa FO, Souza EM, Surek M, Picheth G and Fadel-Picheth CMT (2011) Virulence characteristics and antimicrobial susceptibility of uropathogenic Escherichia coli strains. Genet Mol Res 10: 4114-4125.

19. Vila J and Pal T (2010) Update on Antibacterial Resistance in Low-Income Countries: Factors Favoring the Emergence of Resistance. The Open Infectious Diseases Journal 4: 38-54.

20. Farshad S, Ranjbar R, Japoni A, Hosseini M, Anvarinejad M, Mohammadzadegan R (2012) Microbial susceptibility, virulence factors and plasmid profiles of uropathogenic Escherichia coli strains isolated from children in Jahron, Iran. Arch Iran Med 15: 312-316.

21. Ponnusamy P, Natarajan V, Sevanan M (2012) In vitro biofilm formation by uropathogenic Escherichia coli and their antimicrobial susceptibility pattern. Asian pac J Trop Med 5: 210-213.

22. Sood S and Gupta R (2012) Antibiotic Resistance Pattern of Community Acquired Uropathogens at a Tertiary Care Hospital in Jaipur, Rajasthan. Indian J Community Med 37: 39-44.

23. Jadhav S, Hussain A, Devi S, Kumar A, Parveen S, Gandham N, Wieler LH, Ewers C, Ahmed N (2011) Virulence Characteristics and Genetic Affinities of Multiple Drug Resistant Uropathogenic Escherichia coli from a Semi Urban Locality in India. PLoS ONE 6: 1-7.

24. Kotharri A and Sagar V (2008) Antibiotic resistance in pathogens causing community acquired urinary tract infections in India: a multicenter study. J Infect Dev Ctries 2: 354-358.

25. Azap OK, Arslan H, Serefhanoğlu K, Colakoğlu S, Erdoğan H, Timurkaynak F, Senger SS (2010) Risk factors for extended-spectrum beta-lactamase positivity in uropathogenic Escherichia coli isolated from community-acquired urinary tract infections. Clin Microbiol Infect 6: 147-51.
26. DeBusscher J, Zhang L, Buxton M, Foxman B, BarbosaCesnik C (2009) Persistent extended-spectrum beta-lactamase urinary tract infection. Emerg Infect Dis 15: 1862-4.

27. Clinical and Laboratory Standards Institute (2007) Performance standards for antimicrobial susceptibility testing, Approved standards CLSI Document M100-S17. CLSI: Wayne PA.

28. Rudneva SN, Stoliarova LG, Ershov AA, Pantiukhova VV (1980) Spread and transfer of plasmid resistance in E. coli. Antibiotiki 25: 429-432.

29. Vakulenko SB, Bodunkova LE, Fomina IP, Navashin SM (1982) Genetic control of antibiotic resistance and the R plasmid properties of Clinical Escherichia coli strains. Zh Mikrobiol Epidemiol Immunol 9: 45-49.

30. Krumperman PH (1983) Multiple Antibiotic Resistance Indexing Escherichia coli to identify risk sources of faecal contaimination of foods. App Environ Microbiol 46: 165-170.

31. Tambekar DH, Dhanokar DV, Gulhane SR, Khandelwal VK, Dudhane MN (2006) Antibacterial susceptibility of some urinary tract pathogens to commonly used antibiotics. African J Biotech 5: 1562-1565.

32. Gaind R, Paglietti B, Murgia M, Dawar R, Uzzau S, Cappuccinelli P, Deb M, Aggarwal P Rubino S (2006) Molecular characterization of ciprofloxacin-resistant Salmonella enterica serovar Typhi and Paratyphi A causing enteric fever in India. J Antimicrob Chemother 58: 11391144.

\section{Corresponding author}

Dr. Yashwant Kumar

National Salmonella and Escherichia Centre

Central Research Institute

Kasauli (HP) - 173204

India

Telephone: +91-1792-273252

Email: yasht26@yahoo.co.in

Conflict of interests: No conflict of interests is declared. 